Document downloaded from:

http://hdl.handle.net/10251/53705

This paper must be cited as:

Zehhaf, A.; Benyoucef, A.; Quijada Tomás, C.; Taleb, S.; Morallón, E. (2015). Algerian natural montmorillonites for arsenic(III) removal in aqueous solution. International Journal of Environmental Science and Technology. 12(2):595-602. doi:10.1007/s13762-013-0437-3

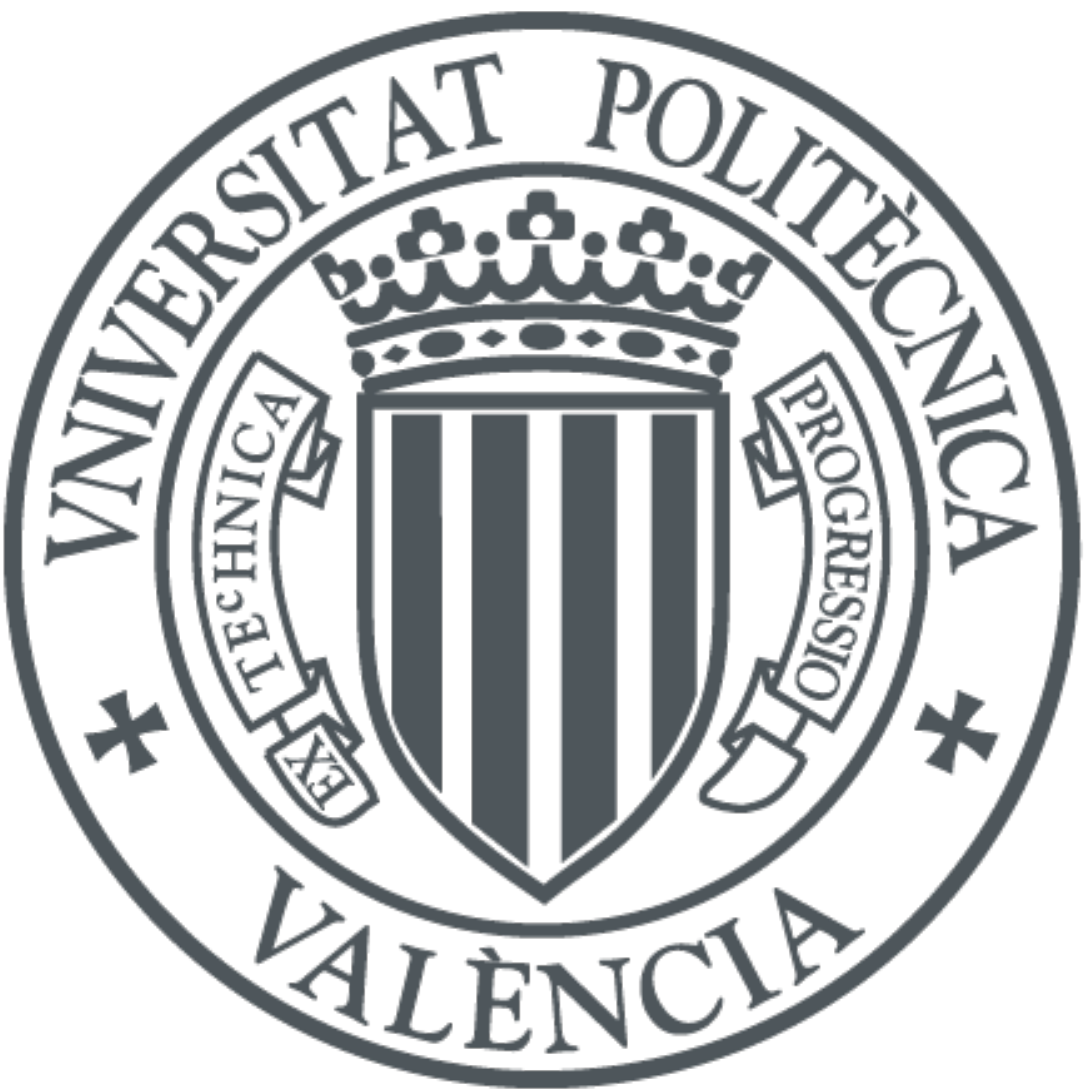

The final publication is available at

http://dx.doi.org/10.1007/s13762-013-0437-3

Copyright Springer Verlag (Germany)

Additional Information 
Full Title

Algerian natural montmorillonites for arsenic(III) removal in aqueous solution

Short Title

Algerian montmorillonites for adsorption of As(III) 


\title{
Algerian natural montmorillonites for arsenic(III) removal in aqueous solution
}

Short title: Algerian montmorillonite for arsenic adsorption

\begin{abstract}
A. Zehhaf ${ }^{\mathrm{a}}$, A. Benyoucef ${ }^{\mathrm{a}}$, C. Quijada ${ }^{\mathrm{b}}$, S. Taleb ${ }^{\mathrm{c}}$, E. Morallón $^{\mathrm{d}}$
${ }^{a}$ Laboratorie de Chimie Organique, macromoléculaire el des Matériaus, Université de Mascara. Bp 763 Mascara 29000 (Algeria).

${ }^{\text {b}}$ Departamento de Ingeniería Textil y Papelera. Universidad Politécnica de Valencia. Pza. Ferrándiz y Carbonell, 1. E-03801 Alcoy (Alicante). Spain.

'Univeristé de Sidi Belabas. Dept. De Chimie. Sidi Belabas 22000 (Algeria).

${ }^{\mathrm{d}}$ Departamento de Química Física e Instituto Universitario de Materiales. Universidad de Alicante. Apartado 99. E-03080 Alicante (Spain).
\end{abstract}

*Corresponding author

e-mail: ghani29000@yahoo.fr

Telf.: +213-771707184

Fax: +213-45930118 


\begin{abstract}
The adsorption of As(III) from aqueous solutions using naturally occurring and modified Algerian montmorillonites has been investigated as a function of contact time, $\mathrm{pH}$ and temperature. Kinetic studies reveal that uptake of As(III) ions is rapid within the first 3 hours and it slows down thereafter. Equilibrium studies show that As(III) shows the highest affinity towards Acidic-montmorillonite even at very low concentration of arsenic. The kinetics of As(III) adsorption on all montmorillonites used is well described by a pseudosecond-order chemical reaction model, which indicates that the adsorption process of these species is likely to be chemisorption. Adsorption isotherms of As(III) fitted the Langmuir and Freundlich isotherm models well. The adsorption of As(III) is pH-dependent obtaining an optimal adsorption at $\mathrm{pH}$ 5. From the thermodynamic parameters, it is concluded that the process is exothermic, spontaneous and favorable. The results suggest that $\mathrm{M}_{1}, \mathrm{M}_{2}$ and Acidic- $\mathrm{M}_{2}$ could be used as low cost and effective filtering materials for removal of arsenic from water.
\end{abstract}

Keywords: Adsorption; Clay; Ion exchange; Arsenic; Montmorillonite. 


\section{INTRODUCTION}

Arsenic (As) is a notoriously toxic element which is ubiquitous in the environment (Zandsalimini et al., 2011; Akter et al. 2011). Arsenic has been classified as a carcinogen agent who poses a high risk to human health if it is released to the environment (Zandsalimini et al., 2011). The main source for people's exposure to As is the contact with water, especially groundwater, which contains As. Arsenicosis is a serious disease mainly caused by drinking As-contaminated groundwater. Many studies have shown that As can also be accumulated in seafood (Lin et al., 2004). Chronic exposure of humans to high concentrations of arsenic is associated with skin lesions, peripheral vascular disease, hypertension, blackfoot disease, and high risk of cancers (Hughes et al., 2002).

A wide range of physical and chemical treatment technologies have been applied for the removal of As from contaminated water, such as coagulation, ultrafiltration, ion exchange, lime softening, adsorption on iron oxides or activated alumina, and reverse osmosis (Akter et al., 2011; Onnby et al., 2012; Daniel et al. 2012; Morallón et al. 2009). One of the disadvantage of these treatments is that the operational costs are high. Consequently there is growing interest in using low-cost materials to remove As from water (Kushwaha et al., 2013; Ali et al., 2013). Among many other kinds of identified low-cost natural sorbents, clay, kaolinite, bentonite, montmorillonite, goethite, spodic, and aquifer materials have high adsorption capacities for As (Elizalde-González et al., 2001; Malakootian et al., 2009). Clays and their modified forms have received attention for use as adsorbents because their easy availability and low cost. Moreover, clays are good adsorbents because of existence of different types of active sites on the surface, which include acid sites and ion exchange sites. Montmorillonite has a net negative charge which is responsible for giving superior activity in comparison with other clays like kaolinite (Bhattacharyya et al., 2008). The adsorption 
capability of clays is usually determined by their chemical composition and pore structure, but also by the $\mathrm{pH}$ of the aqueous medium. (Tang et al., 2009).

The aim of this work is to investigate the adsorption capacity of two Algerian natural montmorillonites and an acid-modified montmorillonite for As(III) ions from aqueous media solutions. The optimum conditions, equilibrium data and adsorption kinetics for As(III) were obtained. The effects of different variables, like As(III) concentration, $\mathrm{pH}$ and temperature have been analyzed. Equilibrium experimental data were fitted to Langmuir and Freundlich isotherm models and a kinetic study has also been performed.

This research has been performed in the University of Alicante (Spain) and Mascara University (Argelia) during the years 2011 and 2012.

\section{MATERIALS AND METHODS}

\section{Reagents}

Arsenic(III)-containing solutions with concentration ranging from 1 to 2500 (mg.L ${ }^{-}$ ${ }^{1}$ )were prepared from analytical grade $\mathrm{As}_{2} \mathrm{O}_{3}$ (Merck) dissolved in $0.1 \mathrm{M} \mathrm{NaOH}$ solution prepared with double-distilled water. The $\mathrm{pH}$ was adjusted to the required value by adding appropriate amounts of $0.1 \mathrm{M} \mathrm{HCl}$ solution.

\section{Preparation of adsorbents}

Two clays were obtained from Algeria: a non sodium montmorillonite from Mostaganem $\left(\mathrm{M}_{1}\right)$ and a sodium montmorillonite from Telemecem $\left(\mathrm{M}_{2}\right)$. By non sodium montmorillonite we refer to a natural montmorillonite which does not contain sodium cations but calcium and others in less concentration. Before its use the adsorbent, the raw-montmorillonites $20 \mathrm{~g}$ was thoroughly washed with tap water to remove unwanted materials such as decomposed organic 
matter, worm, sand, dust particles, etc. and iron containing fine particles, and dried in the Sun for 2-3 days. Then it was crushed to make the particle size of the adsorbent around $1.5 \mathrm{~mm}$. These were then sieved, washed thoroughly (15-20 times) with large volume of tap water to remove the red color of iron, and finally washed with distilled water. Lastly, the material was dried overnight in hot air oven at $378 \mathrm{~K}$ for $4 \mathrm{~h}$ and stored in tightly stoppered glass bottles for later use (samples $\mathrm{M}_{1}$ and $\mathrm{M}_{2}$ ). The $\mathrm{M}_{2}$ sample was activated in acid $\mathrm{H}_{2} \mathrm{SO}_{4}$ is described elsewhere (Zehhaf et al. 2011). Briefly. Acid activation was conducted by heating the mixtures in an oven at $97^{\circ} \mathrm{C}$ for $6 \mathrm{~h}$. acidic- $\mathrm{M}_{2}$ sample was suspended in water, and centrifuged. Obtained precipitate was washed with distilled water until it was free from $\mathrm{SO}_{4}{ }^{2-}$ against $5 \% \mathrm{BaCl}_{2}$ solution and the $\mathrm{pH}$ of the washing was 6.8 . Finally the sample was dried at $378 \mathrm{~K}$ in air until constant weight. This acid activation also removes sodium from its composition (Zehhaf et al., 2011).

\section{Characterization of the clay adsorbents}

The porous texture of all samples was determined by physical adsorption of gases $\left(\mathrm{N}_{2}\right.$ at $77 \mathrm{~K}$ and $\mathrm{CO}_{2}$ at $273 \mathrm{~K}$ ) using an automatic adsorption system (Autosorb-6, Quantrachrome Corporation) after sample out-gassing at $383 \mathrm{~K}$ under vacuum for $4 \mathrm{~h}$. The experimental details are reported elsewhere (Zehhaf et al., 2011).

Nitrogen adsorption at $77 \mathrm{~K}$ was used for determining the total volume of micropores $\left(\mathrm{V}_{\mathrm{DR}}\left(\mathrm{N}_{2}\right)\right.$ ) (pore size smaller than 2nm) by applying the Dubinin-Radushkevich (DR) equation and for determining the specific surface area by the BET equation $\left(\mathrm{S}_{\mathrm{BET}}\right)$, whereas the adsorption of $\mathrm{CO}_{2}$ at $273 \mathrm{~K}$ was used to assess the narrowest micropores $\left(\mathrm{V}_{\mathrm{DR}}\left(\mathrm{CO}_{2}\right)\right)$ (pore size smaller than around $0.7 \mathrm{~nm}$ ) were realized for all three adsorbent materials (Lozano et al., 2009). Porous texture characterization data are summareized in Table 1 . These data indicate that the clays are basically mesoporous materials with some amount of micropores. 
The acidic modification of $\mathrm{M}_{2}$-type montmorillonite gives rise to a significant increase in $\mathrm{S}_{\mathrm{BET}}$ and in the volume of both mesopores and total micropores, whereas the number of narrowest micropores remains unchanged. This result has been attributed to a change from the laminar structure of the pristine clay to a delaminated structure, as revealed by transmission electron microscopy images (Zehhaf et al., 2011). Also, the increase in the volume of mesoand micro-pores was associated with the dissolution of exchangeable cations like $\mathrm{Na}^{+}$and the partial dissolution of structural cations, like $\mathrm{Fe}^{3+}$ and $\mathrm{Mg}^{2+}$, in accordance with X-Ray fluorescence measurements (Zehhaf et al., 2011).

\section{Adsorption experiments}

The clay samples were dried at $80^{\circ} \mathrm{C}$ under vacuum for $24 \mathrm{~h}$ before adsorption. Then, $0.5 \mathrm{~g}$ of adsorbent was put in contact with $50 \mathrm{~mL}$ of an aqueous solution of As(III) with metal

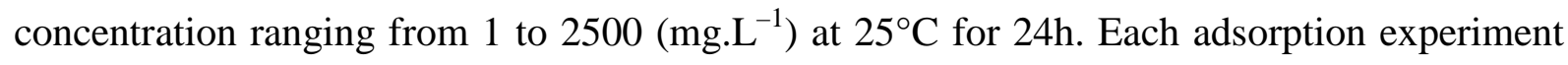
was replicated two times and at three different temperatures (298, 308 and 318K). The pH of the As(III) initial solution ranged from 3 to 12. The concentration of As(III) in the solution was determined by inductively-coupled plasma atomic absorption spectroscopy (ICP-AAS, Perkin-Elmer 7300-DV). As(III) concentration was also determined at different contact times for adsorption kinetics studies.

The amount of adsorbed As(III) at any time, $q_{t}\left(\mathrm{mg} \mathrm{g}^{-1}\right)$ was calculated according to the expression:

$$
q_{t}=\frac{\left(c_{0}-c_{t}\right) V}{m}
$$

Where $q_{t}\left(\mathrm{mg} \mathrm{g}^{-1}\right)$ is the amount of As(III) adsorbed at time t, $c_{0}$ and $c_{t}$ are the initial concentration and concentration at time $t\left(\mathrm{mg} . \mathrm{L}^{-1}\right), V$ the volume of solution (L), and $m$ the 
weight of the montmorillonite (g). When sufficient time has elapsed to reach equilibrium the measured concentration is the equilibrium concentration, $c_{e}$, and Equation (1) yields the amount of As(III) adsorbed at equilibrium, $q_{e}$.

\section{RESULTS AND DISCUSSION}

Effect of contact time on the adsorption of As(III)

Fig. 1. shows the adsorption kinetics of a $2500\left(\mathrm{mg.L}^{-1}\right) \mathrm{As}(\mathrm{III})$ solution on $\mathrm{M}_{1}, \mathrm{M}_{2}$ and Acidic $-\mathrm{M}_{2}$ at $\mathrm{pH}=5$. The adsorption rates (the slope of the plot) of As(III) were fairly high at the beginning of these experiments, and declined throughout the time investigated. After 120 min the amount of adsorbed As(III) remains nearly unchanged, thus indicating that adsorption approaches equilibrium.

In order to determine the adsorption kinetics of As(III) ions, first-order and secondorder kinetics models were checked. The first-order rate expression (Kul et al., 2010) is expressed as follows:

$$
\frac{d q}{d t}=k_{1}\left(q_{e}-q_{t}\right)
$$

Where $q_{e}$ and $\mathrm{q}_{t}$ are the amounts of As(III) adsorbed onto the montmorillonite (mg.g${ }^{1}$ ), at equilibrium and at time $t$, respectively, and $k_{1}$ is the first-order rate constant $\left(\mathrm{min}^{-1}\right)$.

After integration from $t=0$ to $t$ and from $q_{t}=0$ to $q_{e}$, it becomes the Lagergren's rate equation:

$$
\left.\mathrm{log} q_{e} \mathrm{~g} q_{t}\right) \in \mathrm{l} \quad \mathrm{oq} q_{e}-\mathrm{g}_{2.3} t_{\mathrm{C}}
$$


A pseudo-second-order rate law expression was also used; the kinetic rate equation is expressed as (Shah et al., 2009; Urik et al., 2009):

$$
\frac{d i}{d t}=k_{2}\left(q_{e}-q_{t}\right)^{2}
$$

Where $k_{2}$ is the second-order rate constant $\left(\mathrm{g} \cdot \mathrm{mg}^{-1} \cdot \mathrm{min}^{-1}\right)$. At boundary conditions from $t=0$ to $t$ and from $q_{t}=0$ to $\mathrm{q}_{e}$ (Na et al., 2010), the rate law becomes:

$$
\frac{t}{q_{t}}=\frac{1}{k_{2} \cdot q_{e}^{2}}+\frac{t}{q_{e}}
$$

Table 2 includes the relevant kinetic parameters, together with the correlation factor $R^{2}$ from the adsorption kinetics for a $2500\left(\mathrm{mg} . \mathrm{L}^{-1}\right.$ ) As(III) solution, obtained after applying the two models mentioned above.

It can be observed that the pseudo-second-order model provides a better correlation to the kinetic data, with correlation coefficients of 0.99. A pseudo-second-order model for arsenic adsorption process has also been reported previously (Pena et al., 2005; Maity et al., 2005; Na et al., 2010).

\section{Effect of $p H$ on the adsorption of As(III)}

The $\mathrm{pH}$ of the aqueous solution is an important controlling parameter in the adsorption process (Shah et al., 2009). Thus, the effect of $\mathrm{pH}$ of the solution ranging from 3 to 12 was examined. The effect of $\mathrm{pH}$ on the adsorption of As(III) is summarized in Fig. 2. It seems that pH has little effect on the adsorption of As(III) under acidic conditions. This is probably because arsenic ions exist in the form of $\mathrm{H}_{3} \mathrm{AsO}_{3}$ in the pH range 0-9 (Na et al., 2010), and therefore there is a lack of electrostatic interaction between As(III) and the adsorbent surface. 
At $\mathrm{pH}>9$, the anionic form of As(III), dihydrogen arsenite, prevails, an this may explain the additional small drop in the adsorption observed at high pHs. Similar phenomena have been observed in previous studies of the removal of arsenic from water (Pena et al., 2005). Thus, it can be postulated that at least within the range $0<\mathrm{pH}<9$, As(III) is adsorbed through $\mathrm{pH}$ independent complexation reactions on surface hydroxyl sites (Na et al., 2010). To obtain the optimal removal rates, a pH of 5 for As(III) was used in subsequent experiments.

\section{Adsorption isotherms}

Fig. 3. presents the adsorption isotherms of As(III) for the three montmorillonites at $25^{\circ} \mathrm{C}$. Langmuir and Freundlich isotherms were used to analyze the adsorption data. The Langmuir isotherm is based on monolayer adsorption at the active sites of the adsorbent, with no interaction between adsorbate molecules. The linear form of the isotherm is given by:

$$
\frac{c_{e}}{q_{e}}=\frac{1}{q_{0} \cdot K_{l}}+\frac{c_{e}}{q_{0}}
$$

Where $c_{e}$ is the equilibrium concentration of $\mathrm{As}(\mathrm{III})\left(\mathrm{mg} . \mathrm{L}^{-1}\right), q_{e}$ is the amount of As(III) adsorbed on the adsorbent (mg.g ${ }^{-1}$ ), and $q_{o}$ is the adsorption capacity (mg. $\mathrm{g}^{-1}$ ) and $K_{l}$ is a parameter related to the energy of adsorption (L.mg ${ }^{-1}$ ). Plots of $c_{e} / q_{e}$ versus $c_{e}$ values can be used to determine $q_{o}$ and $K_{l}$ (Shah et al., 2009).

The linear form of the Freundlich isotherm is given by:

$$
l \boldsymbol{q}_{e}=l \mathrm{~K}_{f}+\frac{1}{n} l \boldsymbol{a}_{e}
$$


Where $K_{f}$ and $n$ are constants related to adsorption capacity and adsorption strenght, respectively, and $c_{e}$ and $q_{e}$ have the same meaning as in the Langmuir model. A linear plot of $\left(\ln q_{e}\right)$ versus $\left(\ln c_{e}\right)$ yields $K_{f}$ and $n$.

The fitted constants for the Langmuir and Freundlich models are shown in Table 3. $R^{2}$ in the table is the regression coefficient. Notably, the experimental data fit both models well (0.93 $>R^{2}>0.98$ for Langmuir and $0.88>R^{2}>0.93$ for Freundlich). Also, the Langmuir adsorption capacity increases in the order $\mathrm{M}_{2}<\mathrm{M}_{1}<$ acidic- $\mathrm{M}_{2}$, in complete agreement with the observed BET surface areas and porosity of the clays. The values of adsorption capacity are similar to that obtained with Ti-pillared montmorillonite (Na et al., 2010) and higher than the reported with other low-cost material like sawdust of spruce (Urik et al., 2009). The value of the $n$ parameter in the Freundlich isotherm lies between 1 and 10, as it corresponds for a favorable adsorption process (Zehhaf et al., 2011).

\section{Effect of temperature}

Adsorption experiments were carried out in the temperature range $298 \mathrm{~K}$ to $328 \mathrm{~K}$ at an initial arsenic concentration of $2500\left(\mathrm{mg} . \mathrm{L}^{-1}\right)$ and a fixed clay dose of $0.5 \mathrm{~g}$. The adsorption time was long enough to ensure that the adsorption of As(III) reached equilibrium. It was observed that the removal efficiency for As(III) falls with the rise in temperature (Fig. 4) as it is expected for an exothermic adsorption process (see below).

Thermodynamic parameters such as standard free energy $\Delta G$, standard enthalpy $\Delta H$, and standard entropy changes $\Delta S$ can be determined using the equilibrium constant $K_{C}=\frac{q_{e}}{c_{e}}$, which depends on temperature (Shah et al., 2009; Sari et al., 2007):

$$
\Delta G=-R \quad \operatorname{Tn} K_{C}
$$




$$
\mathrm{ln} K_{C}=\frac{\Delta S}{R}-\frac{\Delta H}{R}
$$

where $R$ is the universal gas constant $\left(8.314 \mathrm{~J} \mathrm{~mol}^{-1} \cdot K^{-1}\right)$ and $T$ is the temperature $(K)$.

According to Equation (9), $\Delta H$ and $\Delta S$ can be obtained from the slope and intercept, respectively, of the Van't Hoff plot of $(\ln K)$ versus $(1 / T)$.

In Table 4. The negative values of $\Delta G$ indicate that the adsorption of As(III) onto $\mathrm{M}_{1}$, $\mathrm{M}_{2}$ and acidic- $\mathrm{M}_{2}$ is a spontaneous process. When the temperature decreases, the magnitude of free energy change shifts to high negative value for As(III), suggesting that the process is more spontaneous at lower temperature (Kundu et al., 2007). The negative value of the standard enthalpy change $\Delta H$ for As(III) indicates that the adsorption is exothermic, thereby demonstrating that the process is stable energetically (Kundu et al., 2007). The negative standard entropy change $\Delta S$ value for As(III) correspond to a decrease in the degree of freedom of the adsorbed species.

Analysis of montmorillonites after adsorption by XRD.

XRD patterns of Acidic- $\mathrm{M}_{2}$ with adsorbed arsenite and raw montmorillonite are shown in Fig. 5, the same patterns have been obtained with the other two clays. Table 5 shows the $d_{(001)}$ spacing before and after adsorption for the three clays. For Acidic- $\mathrm{M}_{2}$ this value is $20.05(\AA)$, while for of Acidic- $\mathrm{M}_{2}$-As after the adsorption of As(III) are increased to 23.25 (A) (Table 5).

The $d_{(001)}$ pattern has been increased after the adsorption of As(III), suggesting that arsenic species enters into the interlayer of montmorillonite during the adsorption process (Salavagione et al., 2008). Because of the introduction of polyhydroxy cations into the interlayer space, many active hydroxyl groups are formed. The increase of the interlayer space 
of montmorillonite could be due to the complexation of arsenic with these active hydroxyl groups.

\section{CONCLUSIONS}

Results are presented showing that acidic- $\mathrm{M}_{2}$ is an efficient low-cost material for the removal of As(III) from aqueous solutions. Experimental parameters such as contact time, solution $\mathrm{pH}$ and temperature have been investigated and optimized.

The kinetics of As(III) adsorption on all montmorillonites used is well described by a pseudo-second-order chemical reaction model, which indicates that the adsorption process of these species is likely to be chemisorption. The adsorption isotherms are indicative of monolayer adsorption because the experimental data fit better to Langmuir isotherm.

The removal of $\mathrm{As}(\mathrm{III})$ is $\mathrm{pH}$-dependent. Optimal adsorption of arsenite is obtained at $\mathrm{pH}=5$, is indict the adsorption of As(III) is less favorable under acidic conditions.

Although none of the montmorillonites used is highly effective in the adsorption of As(III) over a wide range of $\mathrm{pH}$, it still can be economically feasible to be used for the removal of arsenic from waste-waters due to their large specific surface area and low cost. Furthermore, the adsorption capacity is significantly increased by acidic treatment and compared with other low-cost adsorbents similar or higher for adsorption of As(III).

The negative values of $\Delta G$ and $\Delta H$ indicate that the adsorption of As(III) onto $\mathrm{M}_{1}, \mathrm{M}_{2}$ and acidic- $\mathrm{M}_{2}$ is a spontaneous and exothermic process. 


\section{ACKNOWLEDGEMENTS}

This work has been financed by the Ministerio de Economía y Competitividad and FEDER(project MAT2010-15273). The National Agency for the Development of University Research (CRSTRA), the Directorate General of Scientific Research and Technological Development (DGRSDT) of Algeria.

\section{REFERENCES}

Ali I, Asim M, Khan TA, 2013. Arsenite removal from water by electroacoagulation on zinczinc and copper-copper electrodes. Int. J. Environ. Sci. Tech. 10:377-384.

Akter A, Ali MH, 2011. Arsenic contamination in groundwater and its proposed remedial measures, Int. J. Environ. Sci. Tech. 8:433-443.

Bhattacharyya, KG, Gupta, SS; 2008. Adsorption of a few heavy metals on natural and modified kaolinite and montmorillonite: A review. Adv. Colloid Interf. Science, 140: 114-131.

Chakravarty S, Dureja V, Bhattacharyya G, Maity S, Bhattacharjee S, 2002. Removal of arsenic from groundwater using low cost ferruginous manganese ore. Water Research. 36: 625-632.

Daniel, R, Rao, AVSP, 2012. An Efficient Removal of Arsenic from Industrial Effluents using Electro-coagulation as Clean Technology Option. Int. J. Environ. Research, 6: 711-718.

Elizalde-González MP, Mattusch J, Einicke WD, Wennrich R, 2001 Sorption on natural solids for arsenic removal. Chemical Engineering Journal. 81: 187-195. 
Hughes MF, 2002. Arsenic toxicity and potential mechanisms of action. Toxicol. Lett. 133:116.

Kartinen EO, Martin CJ, 1995. An overview of arsenic removal processes. Desalination. 103: 79-88.

Kul AR, Koyunchu H, 2010. Heavy metal removal from municipal solid waste fly ash by chlorination and thermal treatment. J. Hazardous Materials. 179: 332-339.

Kundu S, Gupta AK, 2007. Adsorption characteristics of As(III) from aqueous solution on iron oxide coated cement (IOCC). J. of Harzardous Materials. 142: 97-104.

Kushwaha S, Soni H, Ageetha V, Padmaja P, 2013. An insight into production, characterization, mechanism of action of low-cost adsorbents for removal of organics from aqueous solution. Crit. Rev. Environ. Sci. Tech. 43:443-549.

Lin MC, Cheng HH, Lin HY, Chen YC, Chen YP, Liao CM, Chang CGP, Dai CF, Han BC, Liu CW, 2004. Arsenic accumulation and acute toxicity in milkfish (Chanos chanos) from blackfoot disease area in Taiwan. Bull Environ Contam Toxicol. 72: 248-254.

Lozano CD, Suárez GF, Cazorla AD, Linares SA, 2009. Porous texture of carbons. In: Beguin F, Frackowiak E, (Eds.), Carbons for electrochemical energy storage and conversion systems. CRC Press, pp: 115-162.

Malakootian M, Nouri J, Hossaini H, 2009. Removal of heavy metals from paint industry's wastewater using Leca as an available adsorbent. Int. J. Environ. Sci. Tech. 6: 183190. 
Morallón E, Arias-Pardilla J, Calo JM, Cazorla-Amorós D. Arsenic specie interactions with a porous carbon electrode as determined with an electrochemical quart crystal microbalance. Electrochim. Acta, 54:3996-4004.

Na P, Jia X, Yuan B, Li Y, Na J, Chen Y, Wang L, 2010. Arsenic adsorption on Ti-pillared Montmorillonite. J Chem Technol Biotechnol. 85: 708-714.

Ng JC, Wang JP, Shraim A, 2003. A global health problem caused by arsenic from natural sources. Chemosphere. 52: 1353-1359.

Onnby, L, Pakade, V, Mattiasson, B, Kirsebom, H, 2012. Polymer composite adsorbents using particles of molecularly imprinted polymers or aluminium oxide nanoparticles for treatment of arsenic contaminated waters. Water Research, 46: 4111-4120.

Pena ME, Korfiatis GP, Patel M, Lippincott L, Meng X, 2005. Adsorption of As(V) and As(III) by nanocrystalline titanium dioxide. Water Research. 39: 2327-2337.

Salavagione HJ, Cazorla-Amorós D, Tidjane S, Belbachir M, Benyoucef A, Morallón E, 2008. Effect of the intercalated cation on the properties of poly(omethylaniline)/Maghnite clay nanocomposites. European Polymer J. 44: 1275-1284.

Sari A, Tuzen M, Soylak M, 2007. Adsorption of $\mathrm{Pb}(\mathrm{II})$ and $\mathrm{Cr}(\mathrm{III})$ from aqueous solution on Celtek clay. J Hazar dous Materials. 144: 41-46.

Shah BA, Shah AV, Singh RR, 2009. Kinetics of chromium uptake from wastewater using natural sorbent material. Int. J. Environ. Sci. Tech. 6:77-90. 
Tang Q, Tang X, Li Z, Chen Y, Kou N, Su Z, 2009. Adsorption and desorption behaviour of $\mathrm{Pb}(\mathrm{II})$ on a natural kaolin: equilibrium, kinetic and thermodynamic studies. J. Chem. Technol. Biotechnol. 84:1371-1380.

Urik M, Littera P. Sevc J, Kolencik M, Cernansky S, 2009. Removal of arsenic(V) from aqueous solutions using chemically modified sawdust of sprude (Picea abies): kinetics and isotherm studies. Int. J. Environ. Sci. Tech. 6:451-456.

Zandsalimi S, Karimi N, Kohandel A, 2011. Arsenic in soil, vegetation and water of a contaminated region. Int. J. Environ. Sci. Tech. 8:331-338.

Zehhaf A, Benyoucef A, Berenguer R, Quijada C, Taleb S, Morallon E, 2012. Lead ion adsorption from aqueous solutions in modified Algerian montmorillonites. J. Therm. Anal. Calorim. 110:1069-1077 
Table 1. Textural characteristics of non-sodium montmorillonite $\left(\mathrm{M}_{1}\right)$, sodium montmorillonite $\left(\mathrm{M}_{2}\right)$ and acid activated montmorillonite (acidic- $\mathrm{M}_{2}$ ).

\begin{tabular}{|c|c|c|c|c|}
\hline Sample & $\begin{array}{c}S_{\text {BET }} \\
\left(\mathrm{m}^{2} \cdot \mathrm{g}^{-1}\right)\end{array}$ & $\begin{array}{l}V_{\mathrm{DR}}\left(\mathrm{N}_{2}\right) \\
\left(\mathrm{cm}^{3} \cdot \mathrm{g}^{-1}\right)\end{array}$ & $\begin{array}{l}\mathrm{V}_{\mathrm{DR}}\left(\mathrm{CO}_{2}\right) \\
\left(\mathrm{cm}^{3} \cdot \mathrm{g}^{-1}\right)\end{array}$ & $\begin{array}{c}V_{\text {meso }} \\
\left(\mathrm{cm}^{3} \cdot \mathrm{g}^{-1}\right)\end{array}$ \\
\hline $\mathbf{M}_{1}$ & 32 & 0.09 & 0.01 & 0.16 \\
\hline $\mathbf{M}_{2}$ & 25 & 0.09 & 0.01 & 0.16 \\
\hline Acidic- $\mathbf{M}_{2}$ & 140 & 0.19 & 0.01 & 0.68 \\
\hline
\end{tabular}


Table 2. Comparison of the first- and second-order adsorption rate constants, for calculated $\left(\mathrm{q}_{\mathrm{e}, \mathrm{cal}}\right)$ and experimental $\left(\mathrm{q}_{\mathrm{e}, \mathrm{exp}}\right)$ values at 2500 mg. $\mathrm{L}^{-1}$ As(III) concentration and pH = 5.

\begin{tabular}{|c|c|c|c|c|c|c|c|}
\hline \multirow[b]{2}{*}{ Adsorbent } & \multirow{2}{*}{$\begin{array}{c}\text { qe.Exp } \\
\left(\mathrm{mg}^{-g^{-1}}\right)\end{array}$} & \multicolumn{3}{|c|}{ First-order kinetic model } & \multicolumn{3}{|c|}{ Second-order kinetic model } \\
\hline & & $\begin{array}{c}\mathrm{k}_{1} \\
\left(\min ^{-1}\right)\end{array}$ & $\begin{array}{c}\text { qe.Cal } \\
\left(\mathrm{mg}^{-1} \mathrm{~g}^{-1}\right)\end{array}$ & $\mathbf{R}^{2}$ & $\begin{array}{c}k_{2 . a d s} \\
\left(\mathrm{~g} \cdot \mathrm{mg}^{-1} \cdot \mathrm{min}^{-1}\right)\end{array}$ & $\begin{array}{c}\text { qe.Cal } \\
\left(\mathrm{mg}^{-1} \mathrm{~g}^{-1}\right)\end{array}$ & $\mathbf{R}^{2}$ \\
\hline $\mathbf{M}_{1}$ & 10.34 & 0.0196 & 4.33 & 0.77 & 0.0115 & 10.77 & 0.99 \\
\hline $\mathbf{M}_{2}$ & 9.71 & 0.0188 & 5.60 & 0.94 & 0.0098 & 10.08 & 0.99 \\
\hline Acidic- $\mathbf{M}_{2}$ & 14.84 & 0.0225 & 10.07 & 0.93 & 0.0045 & 15.17 & 0.99 \\
\hline
\end{tabular}

Table 3. Freundlich and Langmuir coefficients obtained from the adsorption isotherms of As(III) on the montmorillonite samples at $298 K$ and $\mathrm{pH}=5$.

\begin{tabular}{|c|c|c|c|c|c|c|}
\hline \multirow{2}{*}{ Adsorbents } & \multicolumn{3}{|c|}{ Freundlich coefficients } & \multicolumn{3}{|c|}{ Langmuir coefficients } \\
\hline & $\begin{array}{c}K_{f} \\
\left(\mathrm{mg}^{1-1 / n} \cdot L^{1 / n} \cdot g^{-1}\right)\end{array}$ & $\mathbf{n}$ & $\mathbf{R}^{2}$ & $\begin{array}{c}\mathrm{q}_{0} \\
\left(\mathrm{mg} \cdot \mathrm{g}^{-1}\right)\end{array}$ & $\begin{array}{c}\mathrm{K}_{\mathrm{l}} \\
\left(\mathrm{L} \cdot \mathrm{mg}^{-1}\right)\end{array}$ & $\mathbf{R}^{2}$ \\
\hline $\mathbf{M}_{1}$ & 1.12 & 3.45 & 0.93 & 10.6 & 0.008 & 0.96 \\
\hline $\mathbf{M}_{2}$ & 0.28 & 3.04 & 0.88 & 10.21 & 0.005 & 0.93 \\
\hline Acidic- $\mathbf{M}_{2}$ & 2.60 & 4.43 & 0.93 & 15.03 & 0.01 & 0.98 \\
\hline
\end{tabular}


Table 4. Thermodynamic constants for the adsorption of $\mathrm{As}(\mathrm{III})$ on $\mathrm{M}_{1}, \mathrm{M}_{2}$ and acidic- $\mathrm{M}_{2}$ montmorillonites at various temperatures.

\begin{tabular}{|c|c|c|c|c|}
\hline Adsorbent & $\mathbf{T}(\mathrm{K})$ & $\Delta \mathrm{G}\left(\mathrm{kJ} . \mathrm{mol}^{-1}\right)$ & $\Delta \mathrm{H}\left(\mathrm{kJ} \mathrm{mol}^{-1}\right)$ & $\Delta S\left(\mathrm{~J}^{\prime} \mathrm{mol}^{-1} \cdot \mathrm{K}^{-1}\right)$ \\
\hline $\mathbf{M}_{1}$ & $\begin{array}{l}298 \\
308 \\
318\end{array}$ & $\begin{array}{l}-8.47 \\
-8.07 \\
-7.66\end{array}$ & -20.55 & -40.53 \\
\hline $\mathbf{M}_{2}$ & $\begin{array}{l}298 \\
308 \\
318\end{array}$ & $\begin{array}{l}-7.03 \\
-6.64 \\
-6.26\end{array}$ & -18.53 & -38.58 \\
\hline Acidic- $\mathbf{M}_{2}$ & $\begin{array}{l}298 \\
308 \\
318\end{array}$ & $\begin{array}{l}-10.12 \\
-9.63 \\
-9.14\end{array}$ & -24.82 & -49.31 \\
\hline
\end{tabular}

Table 5. Peak maximum and d-spacing of $\mathrm{M}_{1}, \mathrm{M}_{2}$ and acidic- $\mathrm{M}_{2}$ montmorillonites before and after loading with arsenic.

\begin{tabular}{|c|c|c|c|c|}
\hline \multirow[t]{2}{*}{ Adsorbent } & \multicolumn{2}{|c|}{$\begin{array}{c}\text { Peak maximum, } \\
2 \theta_{\max }(\mathrm{deg})\end{array}$} & \multicolumn{2}{|c|}{$\begin{array}{c}\text { Basal spacing, } \\
d_{(001)}(\dot{A})\end{array}$} \\
\hline & Before & After & Before & After \\
\hline $\mathbf{M}_{1}$ & 5.61 & 5.14 & 15.83 & 17.28 \\
\hline $\mathbf{M}_{2}$ & 6.15 & 5.79 & 14.45 & 15.34 \\
\hline Acidic--M 2 & 5.43 & 4.92 & 16.36 & 18.05 \\
\hline
\end{tabular}


Fig. 1. The adsorption of $A s(I I I)$ by $M_{1}, M_{2}$ and Acidic- $M_{2}$ as a function of contact time at 2500 mg. $\mathrm{L}^{-1} \mathrm{As}(\mathrm{III})$ concentration and $\mathrm{pH}=5$.

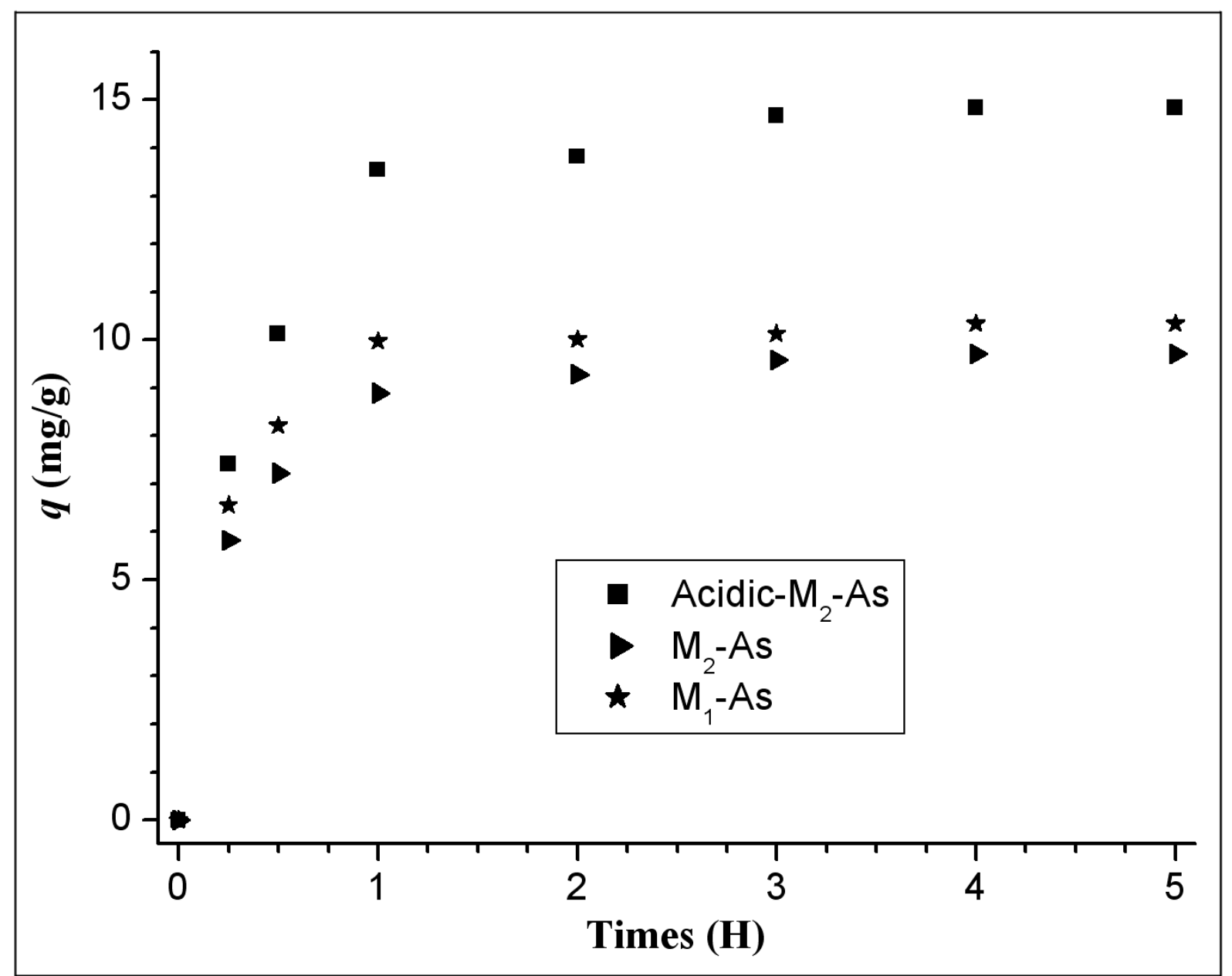


Fig. 2. Effect of $\mathrm{pH}$ value on $\mathrm{As}(\mathrm{III})$ adsorption on $\mathrm{M}_{1}, \mathrm{M}_{2}$ and Acidic- $\mathrm{M}_{2}$ at $2500 \mathrm{mg} . \mathrm{L}^{-1}$ As(III) concentration and $\mathrm{pH}=5$.

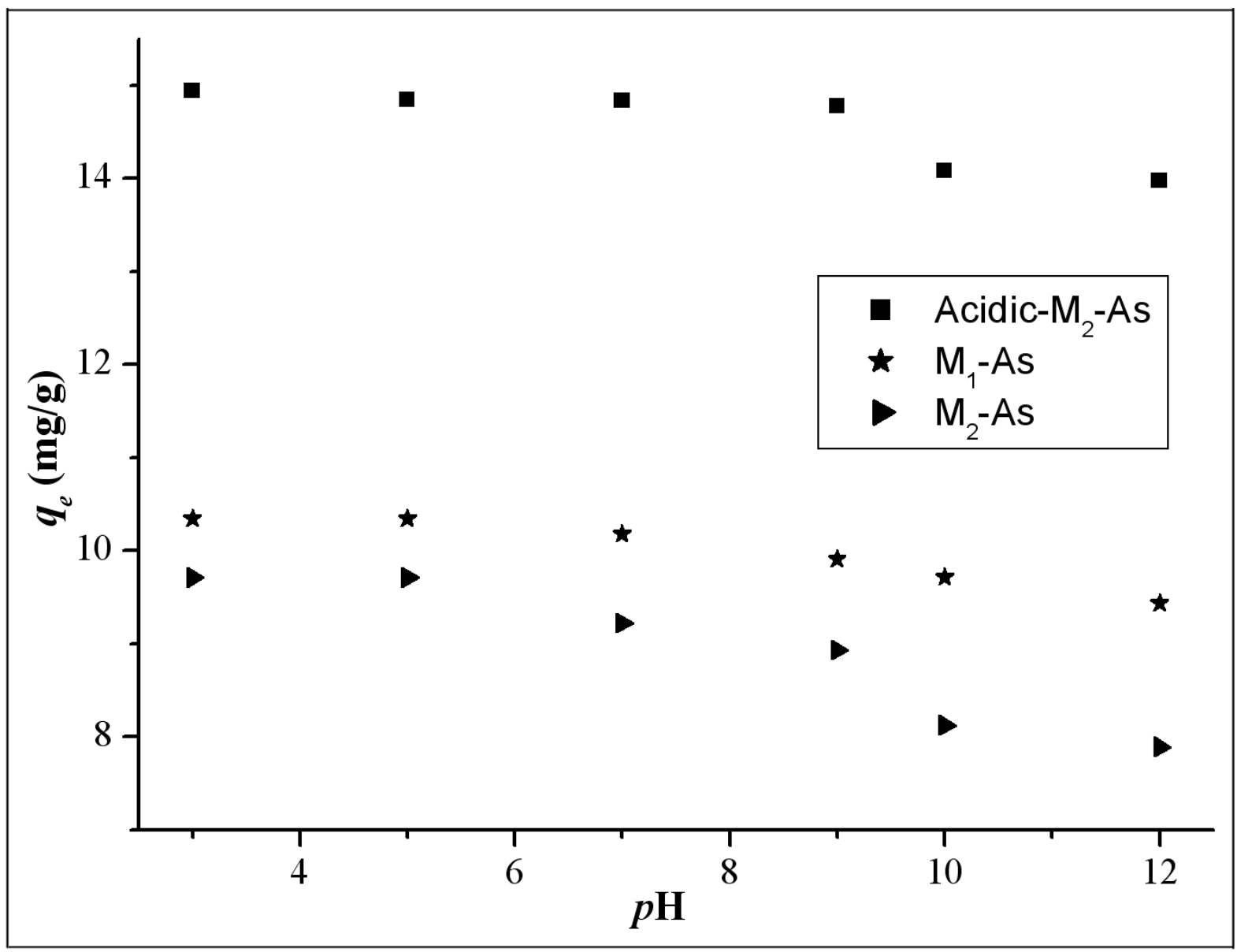


Fig. 3. As(III) adsorption isotherm on $\mathrm{M}_{1}, \mathrm{M}_{2}$ and Acidic $-\mathrm{M}_{2}$ at $\mathrm{pH}=5$.

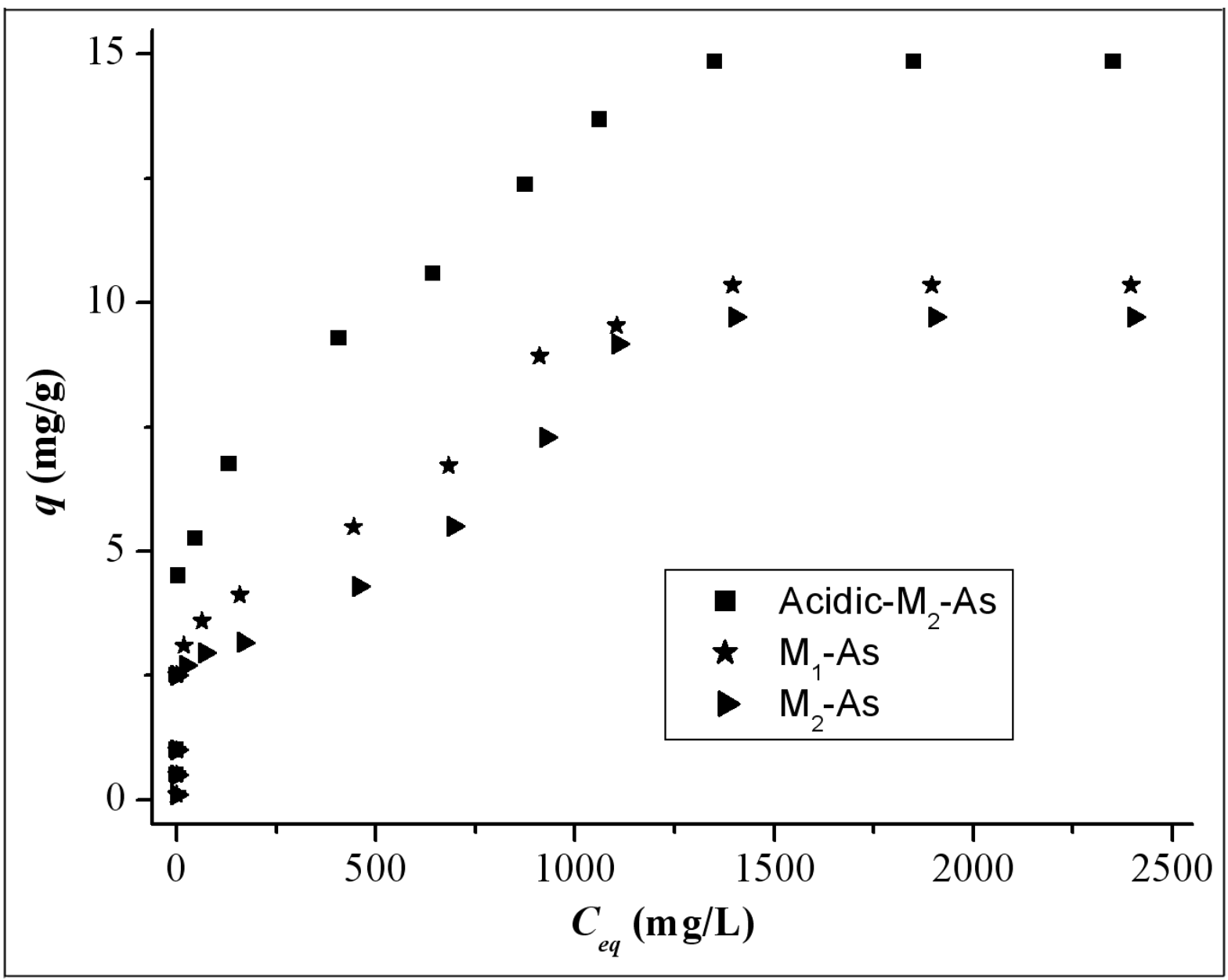


Fig. 4. The effect of temperature on the removal rate of As(III) on $M_{1}, M_{2}$ and Acidic- $M_{2}$ at 2500 mg. $\mathrm{L}^{-1} \mathrm{As}(\mathrm{III})$ concentration and $\mathrm{pH}=5$.

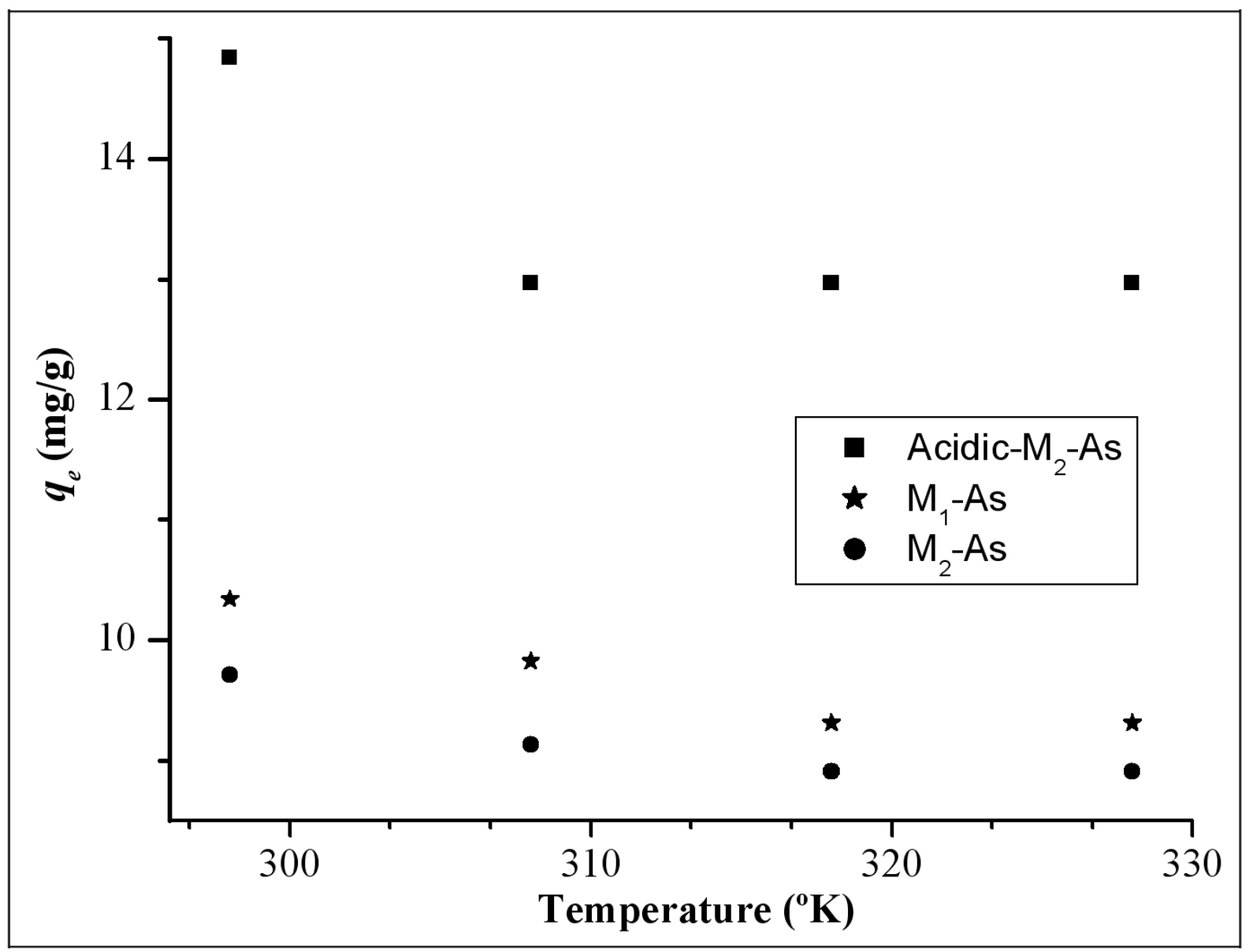


Fig. 5. Powder XRD patterns of Acidic- $\mathrm{M}_{2}$ after and before adsorbed As(III) concentration and $\mathrm{pH}=5$.

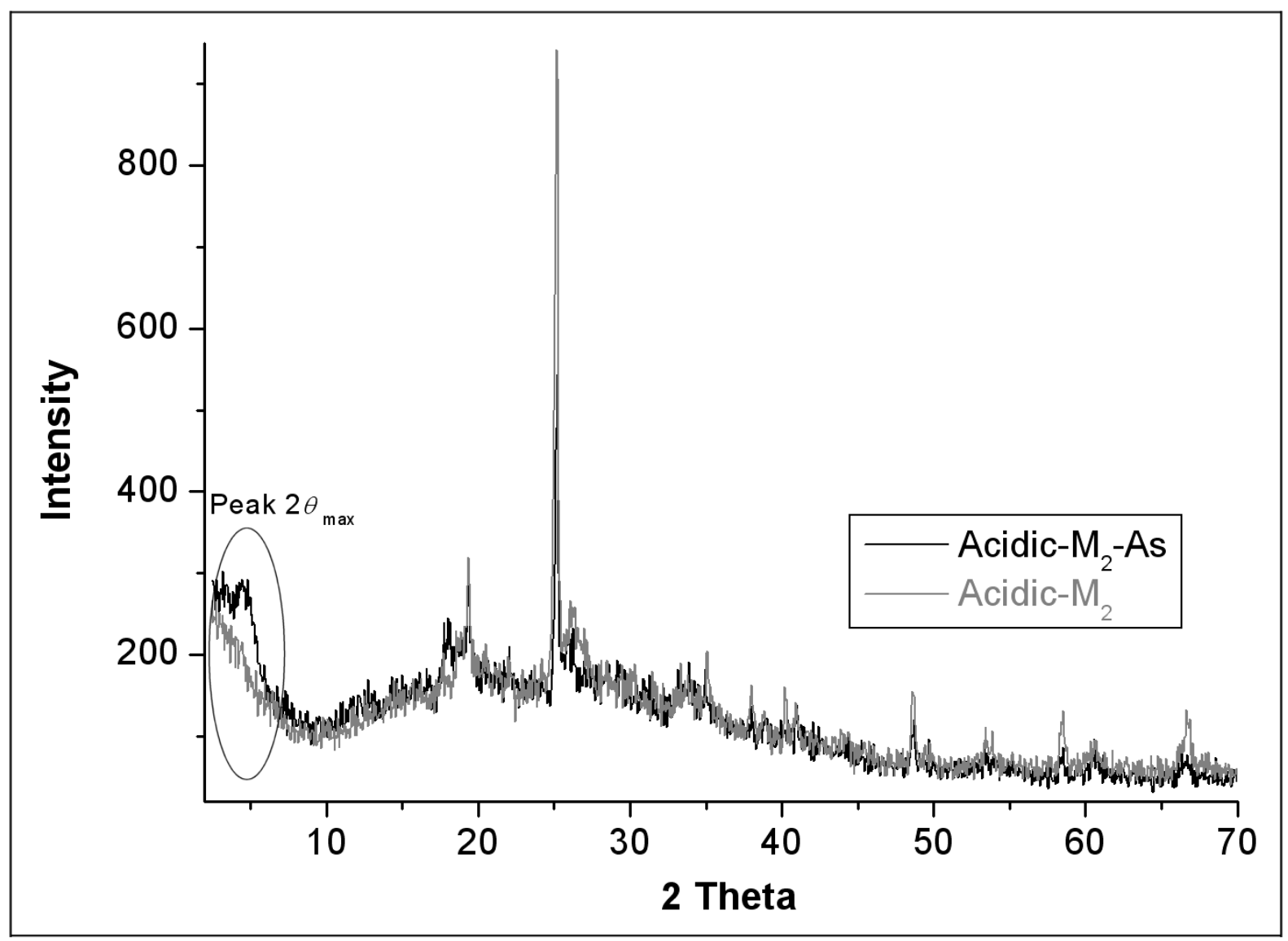

